\title{
Enunciación
}

http://revistas.udistrital.edu.co/ojs/index.php/enunc

DOI: http://dx.doi.org/10.14483/udistrital.jour.enunc.2014.2.a12

AUTOR INVITADO

\section{Elementos para una lectura del libro álbum}

\author{
Fernando Vásquez Rodríguez ${ }^{1}$
}

Para citar este artículo: Vásquez, F. (2014). Elementos para una lectura del libro álbum. Enunciación, 19(2), 333-345.

Cada vez es más frecuente el uso del libro álbum en el aula, por parte de los maestros y maestras. También los padres de familia consideran que este tipo de libros puede ayudar a iniciar y motivar la lectura en sus hijos. Sin embargo, es común la confusión entre libro ilustrado, álbum ilustrado y libro álbum como tal. Tampoco hay la suficiente claridad acerca de la manera en que debe hacerse esta lectura combinada de imágenes y textos, y aún menos los aspectos a tener en cuenta para trabajar didácticamente con este artefacto cultural.

Precisamente, esa ha sido la justificación del presente texto: ofrecer unos elementos para la lectura del libro álbum que a la par que prefiguren una estrategia de la lectura mediada por estos textos, sirvan al mismo tiempo a los educadores como elementos de juicio al momento de elegir o seleccionar los libros álbum de su clase o dentro del plan lector de su institución.

\section{DOS ANTECEDENTES}

Es sabido que los grandes ilustradores ingleses como Walter Crane o Kate Greenaway sirvieron de caldo de cultivo para esta nueva forma de comunicación. Pero, para no salirme del objetivo central de este ensayo, voy a resaltar dos obras que pueden ser pioneras del libro álbum. La primera de ellas es La casa que Jack construyó (Falkoner, 1878). Tomando como referencia una retahíla pensada como un juego de palabras para los más pequeños, Caldecott acompañó dicho texto con dibujos que no solo lo "ilustraban" sino que, además, ampliaban o mostraban asuntos no mencionados por él. Las imágenes, en este caso, dan información adicional a la proporcionada por las palabras. Sabemos por la imagen de las particularidades de la casa de Jack, podemos detallar el vestuario de los personajes y la animada actuación de animales como la rata, el gato, el perro, la vaca... (Figura 1).

Hay momentos en que la imagen se libera del texto y permite adentrarnos imaginativamente en la historia. Caldecott inauguró este formato de juntar dos narraciones que, de alguna manera, se enriquecían mutuamente.

1 Magíster en Educación de la Pontificia Universidad Javeriana. Director de la Maestría en Docencia, Facultad de Educación, Universidad de La Salle. Correo electrónico: fvasquez@lasalle.edu.co 


\section{Figura 1.}
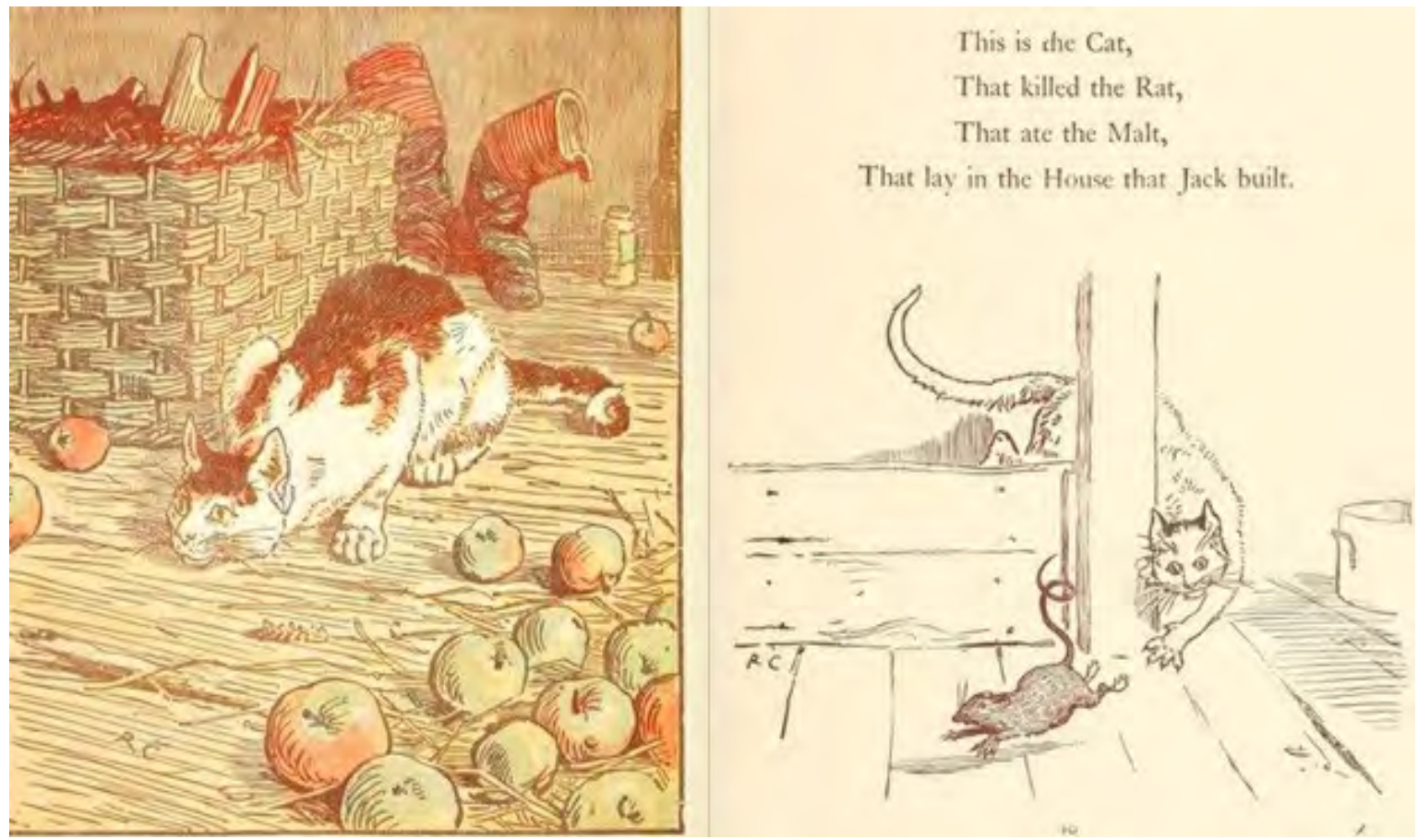

Fuente: R. Caldecott (1878).

El otro ejemplo que también es un hito de referencia en esto del libro álbum corresponde al francés Jean de Brunhoff y su Historia de Babar el elefantito (1931). Aquí hay una perfecta concordancia entre el texto y la imagen: los dos lenguajes se intercomunican a lo largo de todo el libro. Lo más interesante es la forma como Brunhoff construye el personaje, las peripecias por las que pasa y una pensada organización del diseño en el cual se presentan las aventuras. Destaca también la concentración del texto (se cuenta lo esencial sin dar muchos detalles) y un cuidadoso trabajo en el dibujo que elimina elementos decorativos.

De otra parte, el libro cuenta una historia original. Ya no se trata de recrear un texto ajeno sino de construir una obra inédita. Se sabe que Cécile, la esposa de Brunoff, inventó esas historias para sus hijos y su esposo las ilustró con el fin de que ellos se entretuvieran en las noches. Se ve ya en germen otra de las características del libro álbum: la simbiosis entre narrador e ilustrador. La alianza entre alguien que inventa un relato y otro que crea un mundo de líneas y colores paralelo a ese primer universo imaginado. De otro lado, (esto es algo que más adelante subrayaré), el formato de este libro incluye doble páginas intercaladas a lo largo de la historia. Con este recurso se crea un ritmo de lectura diferente al tradicional y se inaugura una nueva práctica lectora al convertir el texto en un objeto o artefacto autónomo (Figura 2).

Por lo demás, con Babar el elefantito — que tuvo un impacto enorme en el público infantil— se inicia también la práctica de darle continuidad a un personaje en futuros libros semejantes. 
Figura 2.

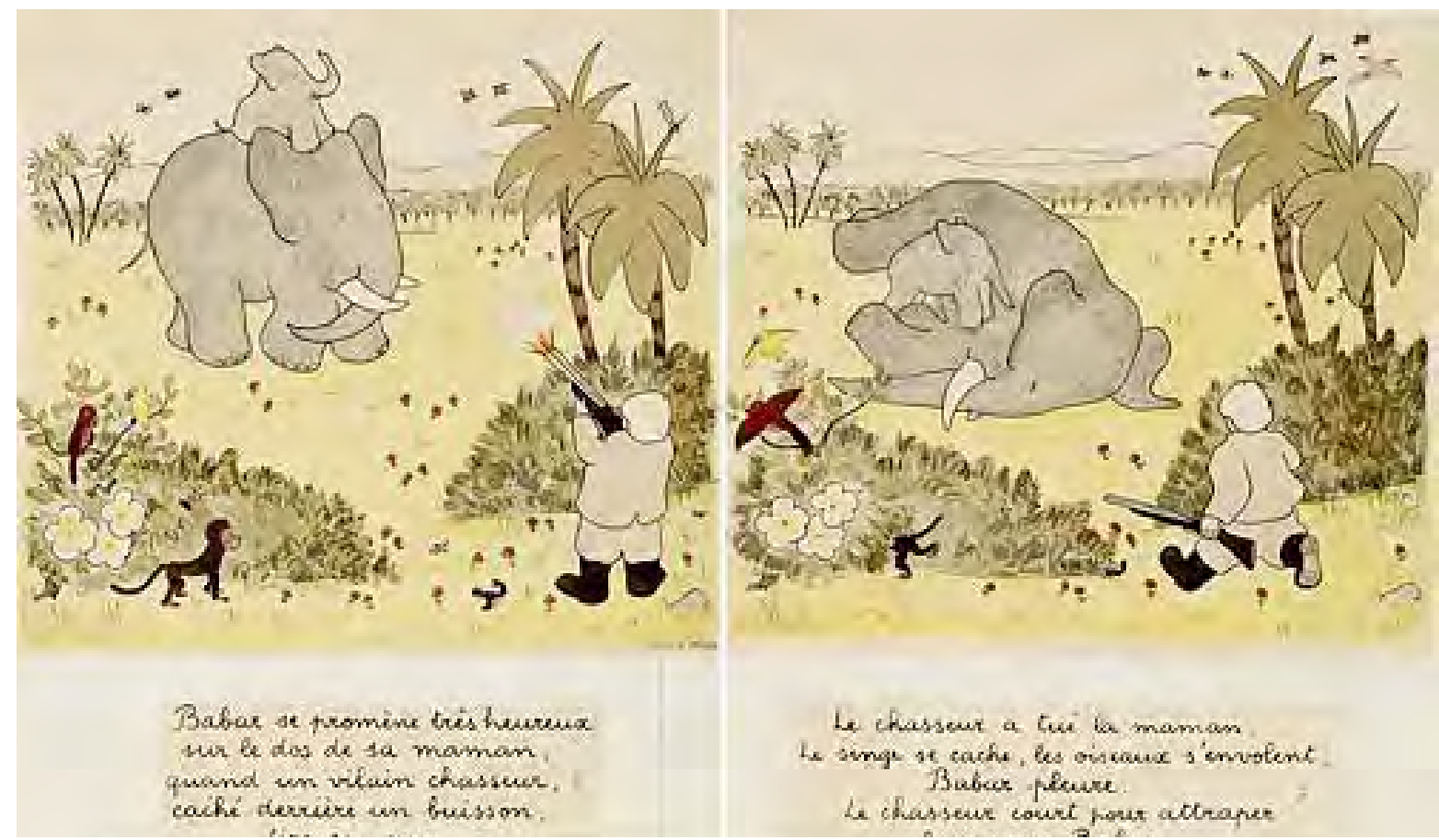

Fuente: J. Brunhoff (2005).

\section{ALGUNAS DISTINCIONES}

Para tratar de aclarar las confusiones o las nominaciones diversas sobre el libro álbum, bien vale la pena retomar un esquema propuesto por María Nikolajeva y Carole Scott, ${ }^{2}$ en el que pueden apreciarse los matices y las gamas de este tipo de libro (Figura 3).

Las autoras colocan, a la manera de un campo de fuerzas, las posibles combinaciones entre la palabra y la imagen. Desde aquellos libros que son únicamente textos narrativos hasta aquellos otros que son álbumes sin palabras. Y desde los libros con imágenes (por ejemplo, los de poesía ilustrada) hasta los libros de exhibición con palabras. Esos textos aunque tienen algunos rasgos del libro álbum no podrían Ilamarse propiamente así; quizá hablaríamos de textos narrativos con ilustraciones. Al centro las dos investigadoras sitúan al libro álbum y sus variantes: los álbumes simétricos (en los que la imagen y texto narran una historia); los álbumes complementarios (en los que o bien la imagen o el texto llenan los intersticios del otro); los álbumes expansivos (en los que la imagen soporta la narrativa textual o en los que el texto depende de la narrativa visual); los álbumes contrapunto (en los que el texto y la imagen se replican o ironizan); y los álbumes silépticos (en los que el texto y la imagen narran historias de manera independiente).

2 Revísese la tesis doctoral Libros que enseñan a leer: álbumes ficcionales y conocimiento literario de María Cecilia Silva-Díaz, dirigida por Teresa Colomer. Retomo la traducción hecha por la autora de la Clasificación de los libros de acuerdo al código (p.35) que, a su vez, está contenida en el libro How Picturebooks Work (Children's Literature and Culture) de María Nikolajeva y Carole Scott (p.12). 


\section{Figura 3.}

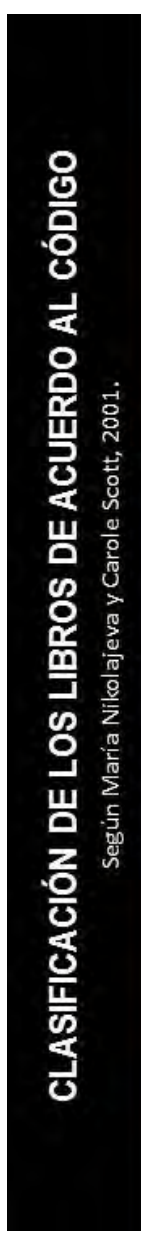

\section{PALABRA}

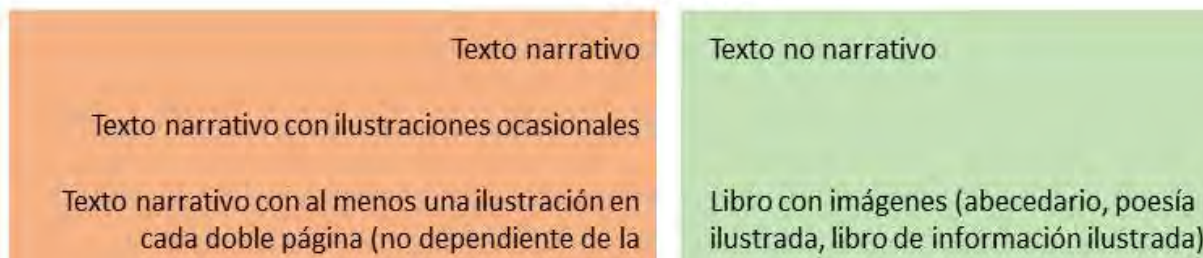

imagen)

Álbum simétrico (dos narrativas redundantes)

Álbum complementario (las palabras y las imágenes llenan los huecos mutuos)

Álbum "expansivo" o "que resalta" (la narrativa visual sostiene la narrativa verbal, la narrativa verbal depende de la narrativa visual)

Álbum de contrapunto (dos narrativas que dependen una de otra)

Álbum siléptico (con o sin palabras) (dos o más narrativas independientes una de otras)

Narrativa ilustrada con palabras (secuencial)

Narrativa ilustrada sin palabras (secuencial)

Álbum sin palabras

Libro de exhibición con palabras (no narrativo, no secuencial)

Libro de exhibición (no narrativo, no secuencial)

\section{IMAGEN}

Fuente: M. Silva-Díaz (2005).

Creo que algunos ejemplos podrían ayudar a comprender mejor lo que las investigadoras norteamericanas han tipificado. Si quisiéramos tomar un álbum sin palabras, podría servirnos una obra de la ilustradora italiana lela Mari (1996), El globito rojo. Aquí la fuerza narrativa la tienen las imágenes. No hay texto, la secuencia se logra únicamente con las variaciones de la forma y unos pocos elementos lineales (Figura 4). Este sería un buen caso de una narrativa ilustrada sin palabras de tipo secuencial.

En el otro extremo podríamos traer a colación el cuento ilustrado de El pescador y su mujer de los hermanos Grimm. Es un texto narrativo clásico en el que se van mezclando imágenes ocasionales (varias de ellas en doble página) pero el peso lo lleva el texto, la historia del cuento. Podría llegarse a pensar que este libro ilustrado pareciera un libro álbum porque las imágenes "ilustran" el texto; sin embargo, ellas mismas no constituyen una narración. Al ponerlas unas detrás de otras no crean una secuencia narrativa (Figura 5). Este ejemplo, como tantos que circulan con formatos más grandes, sería el de un libro ilustrado.

En la mitad de estos dos ejemplos estaría el genuino libro álbum. Para seguir de cerca la clasificación de Nikolajeva y Scott voy a elegir un libro álbum por contrapunto o por ironía. Me refiero al libro álbum El paseo de Rosalía de Pat Hutchins (2011). Acá podemos ver de qué manera el texto y la imagen se complementan de una manera muy interesante: el texto cuenta de manera sencilla los diferentes sitios por los 
que pasa una gallina al dar un paseo cotidiano. La imagen narra lo que el texto no nos dice: un zorro la va persiguiendo y, en esa cacería, siempre le acaece un percance o sufre algún accidente. Texto e imagen se contrapuntean, se enriquecen mutuamente. Una cosa es la que sabemos mientras leemos el texto y otra, la que nos van narrando las imágenes. Los dos lenguajes se potencian de una manera excepcional (Figura 6).

\section{Figura 4.}
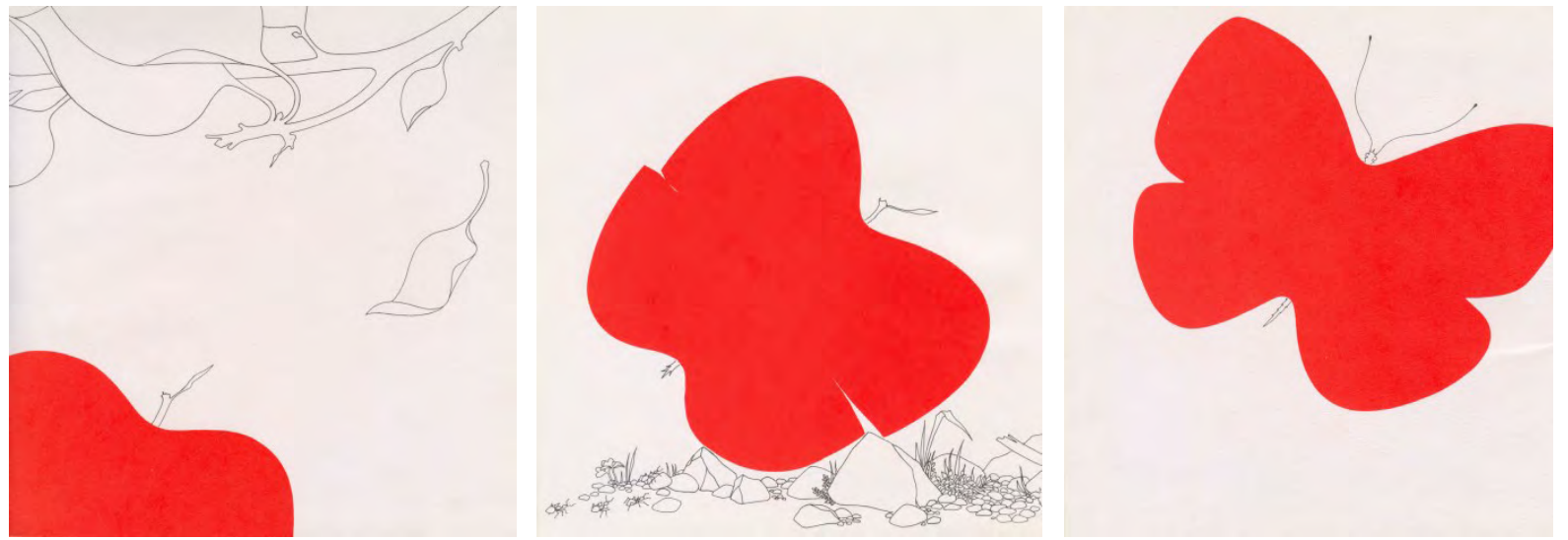

Fuente: I. Mari (1996).

\section{Figura 5.}

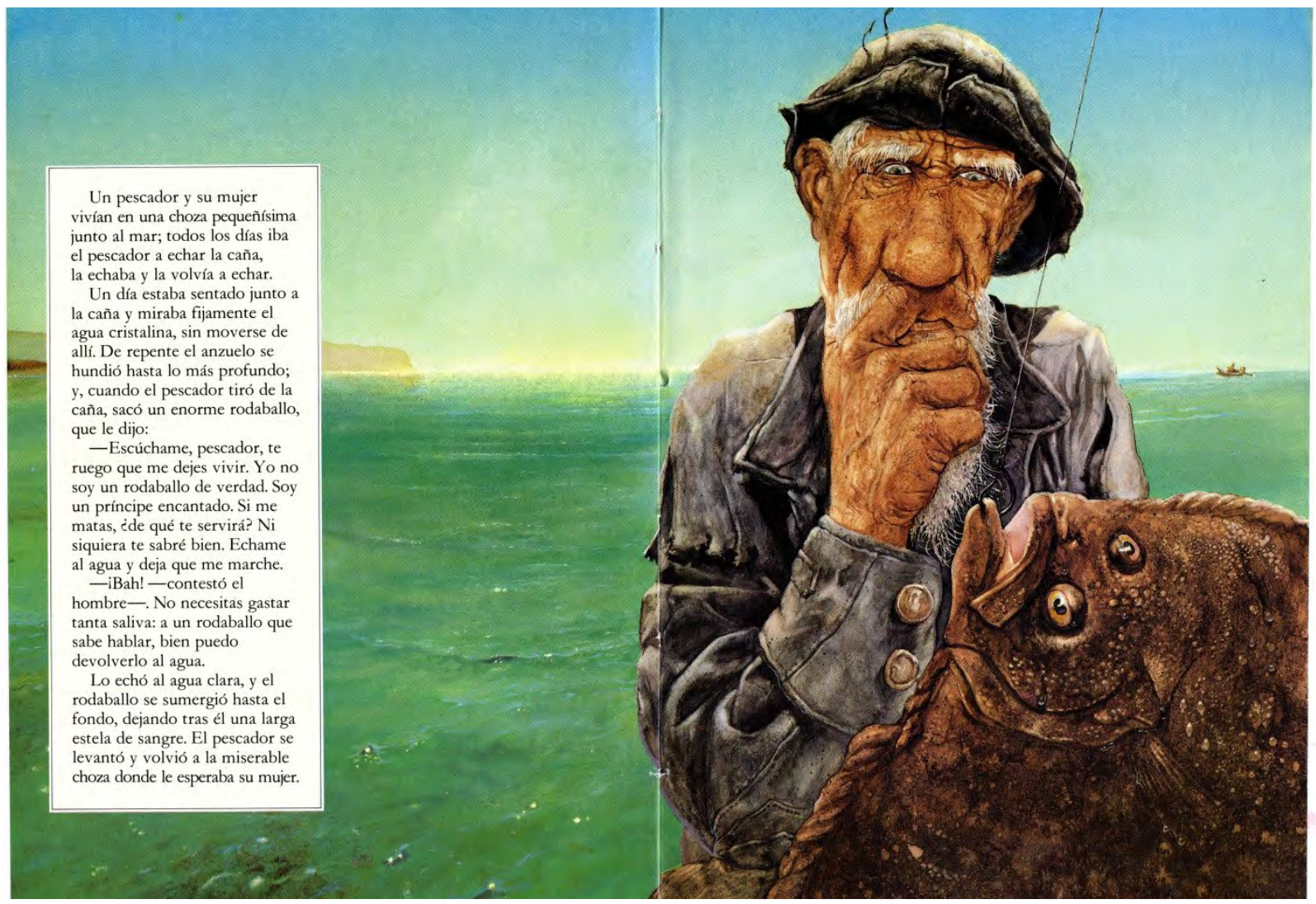

Fuente: J. Grimm y W. Grimm (1984). 
Figura 6.

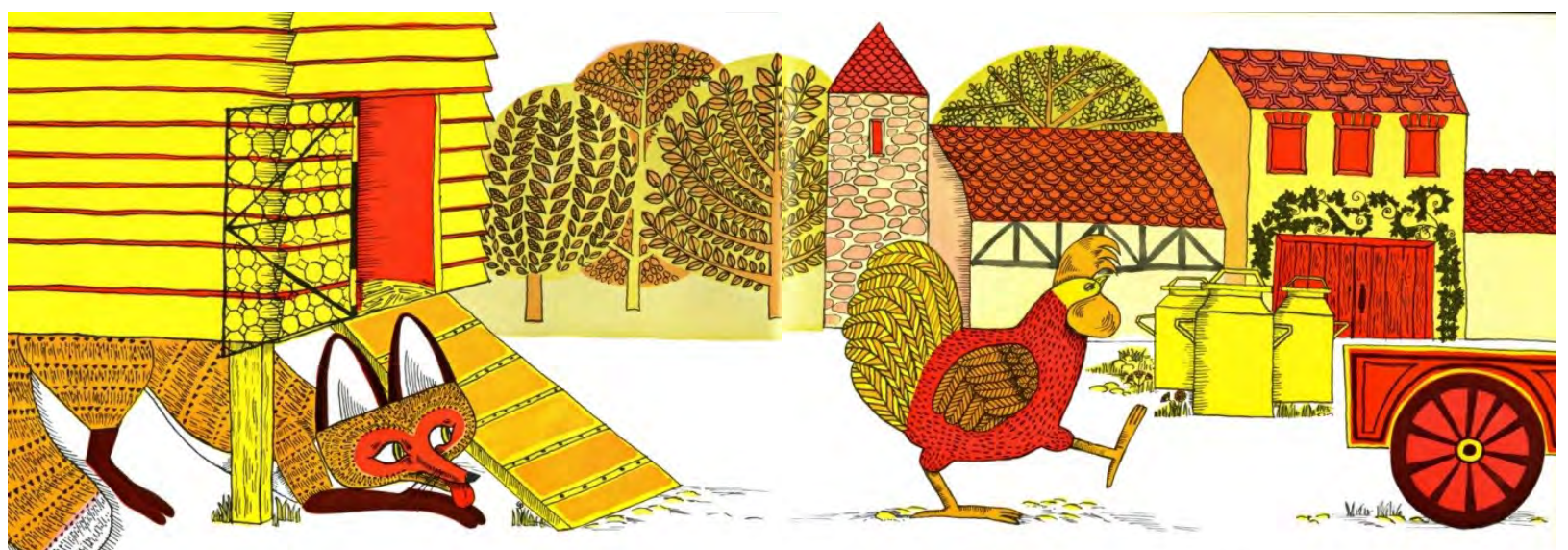

La gallina Rosalía salió a pasear,

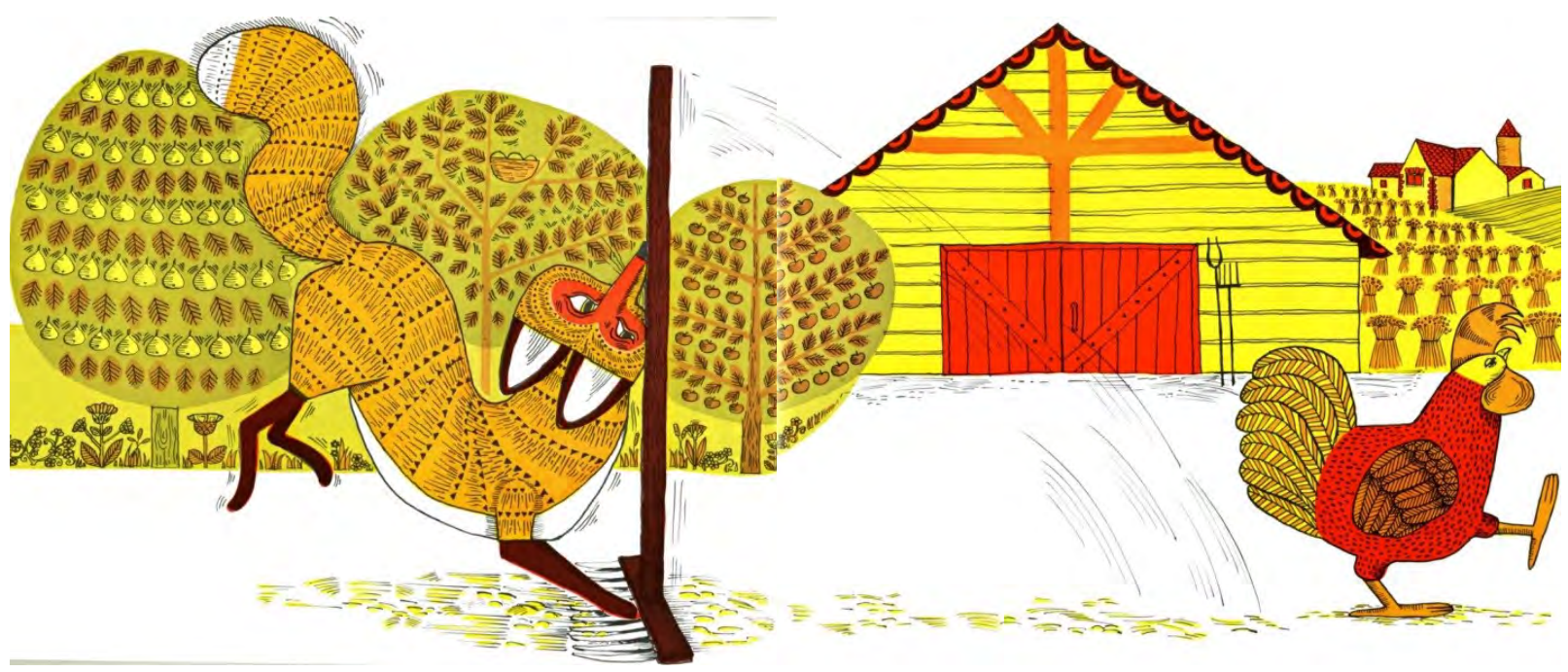

Fuente: P. Hutchins (2011).

Como lo han señalado estudiosos del libro álbum, entre uno y otro extremos hay matices, variaciones, cruces e intercambios sujetos a la creatividad e innovación de autores e ilustradores. Con esto en mente ya podemos adelantar una definición: un libro álbum es aquel tipo de libro en el que las imágenes y el texto guardan una relación de correspondencia, interacción o interdependencia significativa. En el libro álbum tanto el texto como la imagen son igualmente importantes y su lectura requiere atender a los elementos propios de la narrativa como aquellos otros propios de la imagen. 


\section{GRUPOS DE ELEMENTOS}

Ya que el libro álbum combina dos tipos de lenguaje es necesario atender a varios elementos en su lectura. ${ }^{3}$ Aunque cada obra prioriza o destaca un grupo de ellos, lo cierto es que en la práctica debemos conocer o utilizar didácticamente este abanico de características. Lo que no debemos hacer es seguir leyendo el libro álbum como si fuera el texto de un cuento tradicional desconociendo toda esta riqueza comunicativa.

Mi propuesta está organizada en cinco grupos de elementos. Desde el aspecto más físico del libro álbum hasta aspectos retomados del cómic o el cine. Más que ser un listado definitivo, lo que me interesa es fijar algunos referentes a partir de los cuales se pueda orientar o sacar el mayor provecho de este artefacto cultural que, como se puede apreciar hoy en día, ya no tiene como objetivo exclusivamente a los más pequeños.

\section{Elementos materiales}

Un primer conjunto de elementos corresponde a aquellos aspectos físicos del libro álbum. Me refiero a la portada, la contraportada, las guardas y el formato. Cada uno de estos elementos puede ser capitalizado por el docente o al menos no debe ser descuidado al momento de hacer una lectura del libro álbum en clase.

A veces perdemos información valiosa acerca del autor y el ilustrador del libro que está consignada en la contraportada, o pasamos por alto el formato: si es vertical, apaisado, cuadrado o troquelado. En cuanto artefacto cultural, cada elemento material del libro álbum comunica cosas diferentes e invita a una lectura particular.

Piénsese no más en la poca importancia de una lectura de las guardas. Quizá no reparamos en el color que anuncia o le da un telón de fondo a la historia; o no nos percatamos de que determinadas ilustraciones son indicios del contenido. Ese es el caso de La sorpresa de Nandi de Eileen Browne (1996) en el que las guardas del inicio nos muestran los diferentes frutos que la protagonista lleva en su cesta, y las guardas del final presentan los distintos animales con los que ellas se encuentra y que van a ir devorando página a página los mencionados frutos. En este caso, las guardas operan como indicios e invitan a una lectura abductiva o inferencial ${ }^{4}$ (Figura 7).

Figura 7.

Fuente: E. Browne (1996).

3 Sigue siendo una obra de consulta de gran utilidad el texto Leer y mirar el libro álbum: ¿ un género en construcción? De Fanuel Hánan Díaz; de igual modo es valioso el trabajo Cruce de caminos. Álbumes ilustrados: construcción y lectura de Fernando Zaparaín y Luis Daniel González (2010).

4 Sobre este tipo de lectura no sobra recordar dos textos esenciales: El signo de los tres. Dupin, Holmes, Peirce, de Umberto Eco y Thomas A. Sebeok (1989) y El queso y los gusanos de Carlo Ginzburg (1986). 


\section{Elementos de diseño gráfico}

Este es un segundo grupo de elementos en los que entran, entre otros, la doble página, la tensión verticalidad-horizontalidad, la simultaneidad visual, la tipografía.

Al igual que en el punto anterior, estos aspectos a veces son invisibilizados por el lector del libro álbum. Decíamos atrás que la doble página amerita una atención especial: con ella, los ilustradores o creadores de la historia buscan cambiar el ritmo de lectura y hacer que la tensión entre la imagen (la verticalidad) y el texto (la horizontalidad) Ilegue a momentos dramáticos. O, como sucede en muchísimas obras, el diseño del libro muestre al mismo tiempo lo que acaece en tiempos diferentes o en distintas situaciones anímicas de un personaje. Bastaría consultar el abecé de los diseñadores gráficos ${ }^{5}$ para enriquecer nuestro vocabulario al hacer una lectura del libro álbum con los estudiantes.

Me gustaría detenerme por unos momentos en la tipografía, entre otras cosas por su flagrante omisión por parte de los educadores al realizar una lectura del libro álbum. Además de las posibilidades del tipo de fuente (helvética, garamond...) la tipografía (con un cambio de tamaño) puede comunicar cercanía o lejanía, señalar una entonación diferente en lo dicho por algún personaje, indicar una inflexión en el diálogo o advertirnos de una exclamación o un grito. Digamos que la tipografía hace las veces del habla viva con sus matices, inflexiones y tonalidades. En esto, especialmente en las onomatopeyas, el libro álbum retoma cierta sintaxis del cómic.

Para darnos una idea de lo dicho, miremos con algún detalle la obra Benjamino de María Teresa Andruetto (2012), ilustrada por Cynthia Orensztajn. El texto usa a lo largo de las 52 páginas una tipografía palo seco (una variante de la helvética) de unos veinte puntos. Esta fuente identifica al narrador de la historia. Esa tipografía cambia de tamaño justo cuando la madre de Benjamino lo llama varias veces después de que la vaca se lo comió. El cambio de tamaño nos advierte del grado de entonación. La madre grita, como es un grito la respuesta del hijo desde el fondo de la panza de la vaca. De otra parte, el texto cambia de fuente en algunas partes para indicar la voz de los personajes. (Figura 8).

Figura 8.

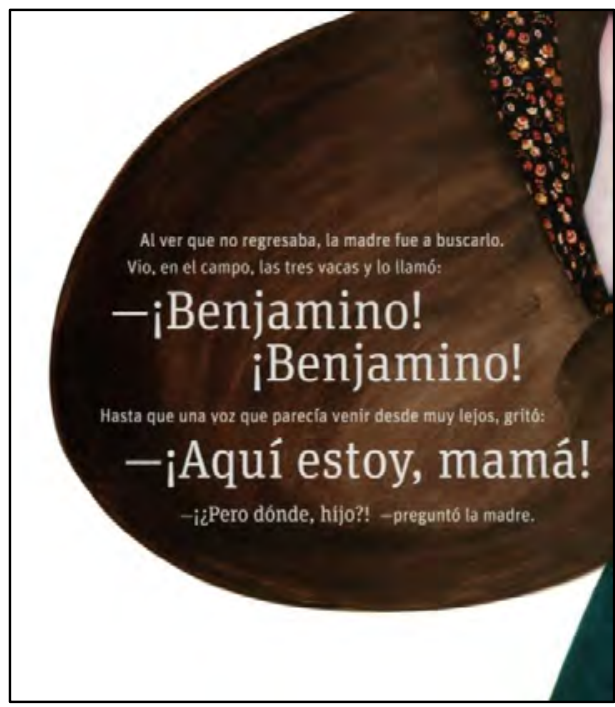

El lobo se quedó pensando un momento y luego habló: -iQuë lëndë pëlëmë!

-¡No lobo, así no! -insistió Benjamino- ¡Decilo bien! -iQuëë lëëndë pëlëëmë! -repitió con esfuerzo el lobo.

Fuente: T. Andruetto (2012).

5 Sirva de consulta estos textos: Bases del diseño gráfico de Alan Swan y El arte de ilustrar libros infantiles. Concepto y práctica de la narración visual de Martin Salisbury y Morag Styles (2012). 


\section{Elementos de la imagen}

Aunque algunos de estos elementos forman parte de las herramientas de los diseñadores gráficos, los he puesto en un lugar independiente para subrayar su importancia y reiterar la necesidad de que los educadores se alfabeticen en este otro tipo de lenguaje ${ }^{6}$.

Son muchos los elementos que entran en este grupo: el punto, la línea, el soporte, el color, la perspectiva, la luz, la textura, los elementos decorativos, la composición. Estos elementos al combinarse construyen una sintaxis y una semántica comunicativas. ${ }^{7}$ Cuánto gana el color de una imagen cambiando el tinte, la saturación o el tono; cuánto cambia la lectura de un libro álbum si presenta una perspectiva de frente o área; cuánto agrega a la narración de una obra si hay frontones o viñetas.

Para no extendernos en esta variedad de elementos, destacaremos el aspecto del soporte. Nos referimos a la manera como es presentada la imagen; es decir, si se usa lienzo, papel, madera, plastilina, cartón o tela. Además de las cualidades propias de cada una de estas técnicas, lo interesante es hacerlas evidentes a los estudiantes y distinguirlas en cada caso. Porque esa decisión del ilustrador no es gratuita: puede convertirse en una clave simbólica del relato o servir de contrapunto o ironía a la narración escrita. Otras veces, el soporte ya es de por sí una propuesta creativa o innovadora y contribuye de manera definitiva a darle identidad al libro álbum.

Tomemos un ejemplo: Nadarín de Leo Lionni (2008). La combinación de las acuarelas con troqueles estampados (especialmente para los peces) contribuye a crear un ambiente marino en el que transcurre la historia. En esta ocasión el soporte no es ningún tipo de decorado sino un elemento sustancial al libro álbum. Los estampados imitan las formas de las esponjas de mar y los troqueles semejan los bosques de algas o los cardúmenes. (Figura 9).

\section{Elementos narrativos}

Este grupo de elementos responde a los propios del relato: la historia, los personajes, la trama, el narrador, el espacio y el tiempo, la focalización, los diálogos. Quizá estos aspectos sean los más conocidos por los docentes y, en consecuencia, a los que les prestan mayor importancia.

A pesar de ello, bien vale la pena recordar que la historia puede ser real o ficticia y necesita de un conflicto como detonante; que los personajes responden a una caracterización externa (vestuario, rasgos físicos) e interna (forma de pensar, temperamento) y se desempeñan como protagonistas o personajes secundarios; que la trama corresponde a la organización de las acciones y que obedece — según los cánones clásicos-a un planteamiento, un conflicto, un nudo y un desenlace; que el narrador puede adoptar un punto de vista externo o interno a la historia y asumirse como testigo, protagonista o saber de los pensamientos y las intenciones de los personajes. O tener presente las características del espacio y el tiempo, la atmósfera y el momento en que se ubica la historia. O reparar en los tipos de diálogo y el modo de efectuarse entre los personajes.

Insisto en que varios de estos elementos son de uso frecuente por los docentes porque son los propios de la lectura de los cuentos ${ }^{8}$. Y si bien son esenciales al libro álbum, constituyen apenas —por decirlo así- el cincuenta por ciento de la obra.

6 Para lograr este cometido es valiosa la obra La sintaxis de la imagen. Introducción al alfabeto visual de Donis A. Dondis (1992); de igual modo es ilustrativo el texto Imagen y educación de Miguel Ángel Santos Guerra (1998).

7 Sirva recordar el trabajo de Vasili Kandinsky, Punto y línea sobre el plano. Contribución al análisis de los elementos pictóricos (1975), en el que muestra las posibilidades expresivas del punto y la línea al ponerlas en un plano.

8 Dos referencias sobre este aspecto merecen traerse a colación: El cuento, de Pilar Leal, Ignacio Martín y Rafael Pontes (2005) y Cómo escribir relatos de Silvia Adela Kohan (1999). 


\section{Figura 9.}

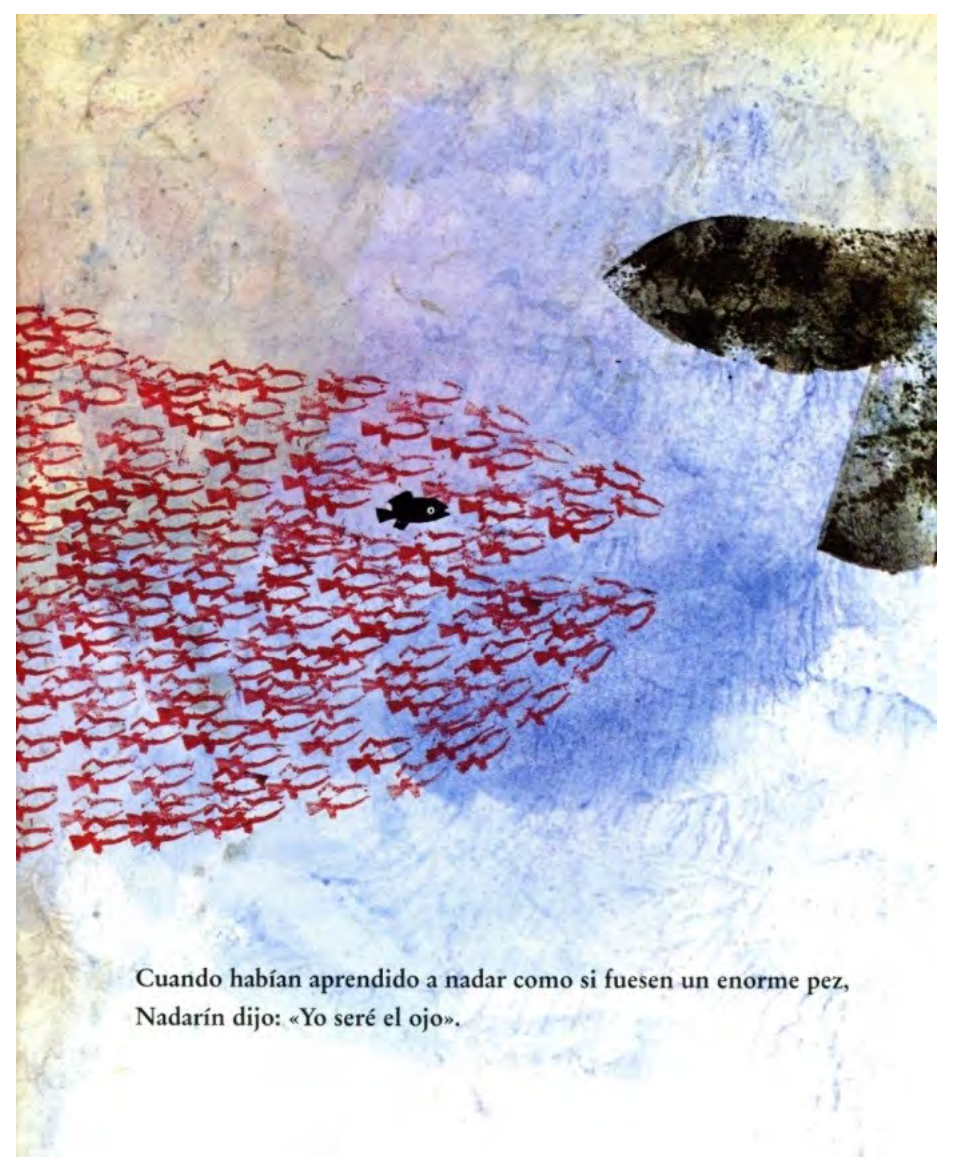

Fuente: L. Lionni (2008)

Cabría acá detenernos en el asunto de la trama y analizarla en Los tres cerditos, en la versión de David Wiesner (2003). La trama es compleja porque, sobre la base inicial de un cuento tradicional, se van intercalando otras historias, a la manera de incisos textuales y gráficos, hasta volver a empalmar con la historia del comienzo. La trama mantiene una estructura tradicional pero en su desarrollo van insertándose otras historias paralelas. El planteamiento y el conflicto corresponden a lo esperado pero es en el nudo y el desenlace de la historia donde se interviene o se recrea el cuento. La complejidad de la trama es acompañada por una propuesta gráfica en la que se aprecian esas mismas intercalaciones o inserciones en el texto. (Figura 10).

\section{Elementos cinematográficos}

Este último grupo de elementos perfectamente podría formar parte del grupo de la imagen pero, dado su empleo abundante en los libros álbum contemporáneos, ameritan un lugar independiente.

Aquí se agrupan elementos como la secuencia, los encuadres, los planos, el recorte de la figura, la visión subjetiva, la angulación. Son aspectos que el libro álbum ha tomado del cine y los ha ido incorporando en el tratamiento de la imagen. Obsérvese, para retomar un elemento, el uso que los ilustradores hacen de los planos: desde el gran plano general, el plano general, el plano medio, hasta 
el primer plano o el plano detalle. O cómo utilizando el picado o el contrapicado en la angulación crean situaciones de alto dramatismo en la historia. Es común hoy que el ilustrador use el encuadre para llevar al lector a focalizar su atención en una situación o para cargar de valor comunicativo un detalle específico. Y si recorta o edita una figura, lo hace con la misma lógica de los directores de cine: para aumentar la tensión, para crear un suspenso o para meter al espectador en un campo ficcional o imaginario autónomo.

Tendríamos bastantes obras de dónde escoger si quisiéramos ilustrar este grupo de elementos. Podríamos acudir al ya clásico El libro en el libro en el libro de Jörg Müller (2002) o En el desván de Hiawyn Oram y Satoshi Kitamura (1995). Un tanto por gusto personal, me centraré en El árbol rojo de Shaun Tan. En esta obra son destacables los encuadres empleados, el cambio de planos y la angulación utilizada. La ilustración reproducida en la figura 11 muestra una secuencia en la que cada cuadro (desde un plano detalle) va ampliando el foco de visión hasta una dimensión inesperada. El efecto de zoom out contribuye a reforzar y poner en otro lenguaje el lento estado de ánimo de la esperanza. Por lo demás, el haber simbolizado este deseo en un caracol subraya la sensación de demora y pesadez.

\section{Figura 10.}

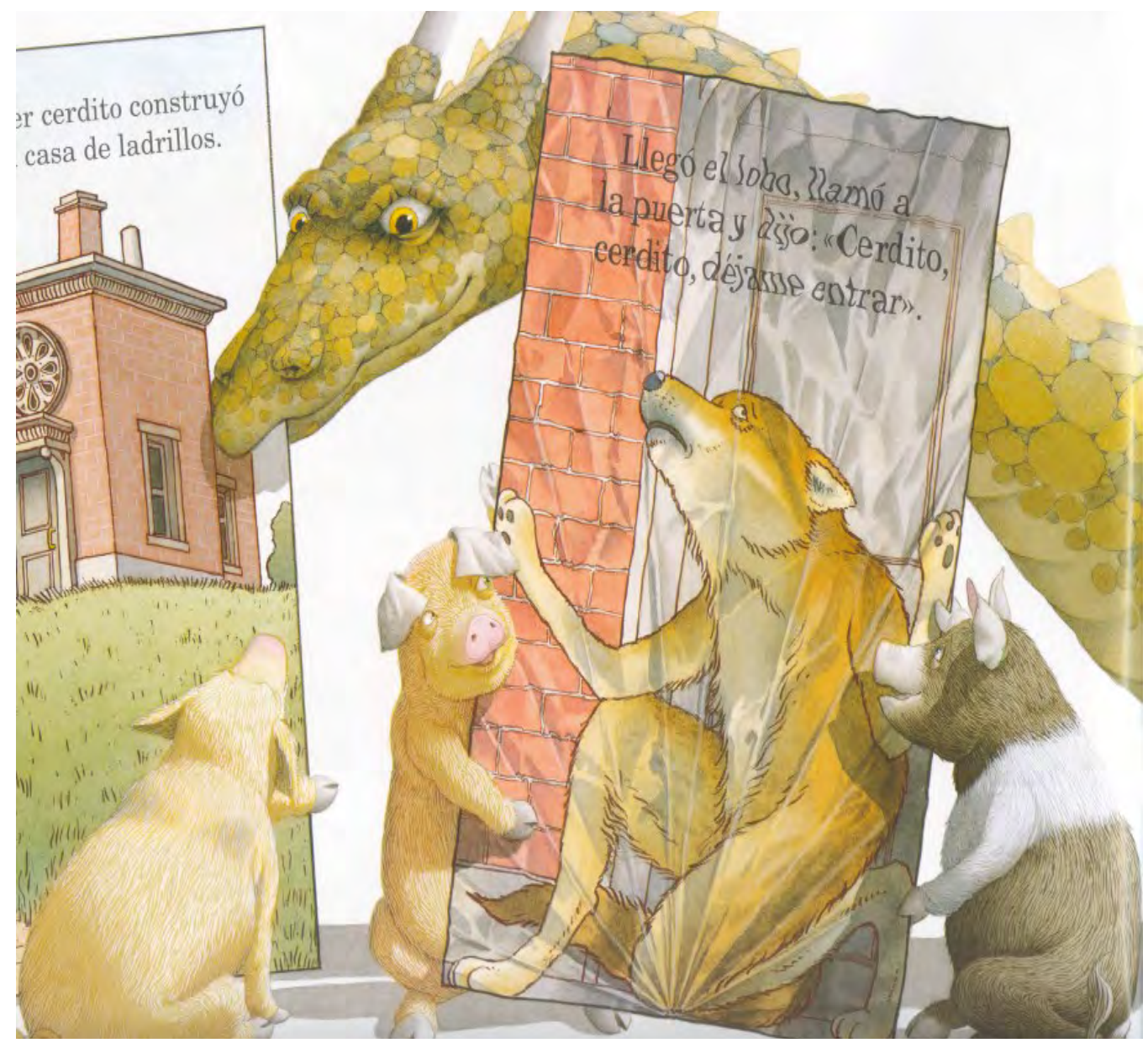

Fuente: D. Wiesner (2003). 


\section{Figura 11.}

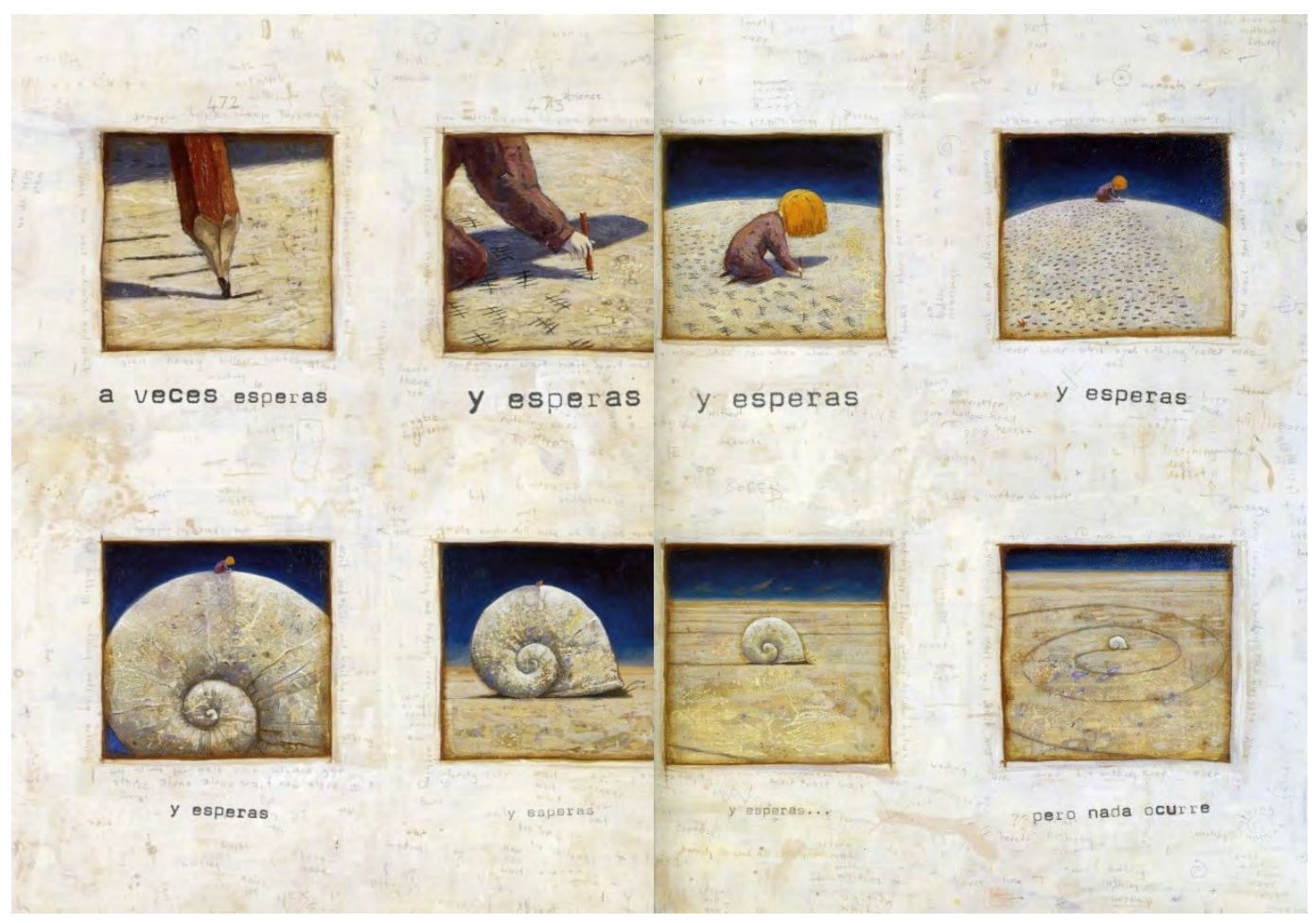

Fuente: H. Oram (1995).

\section{EPÍLOGO}

Las ideas anteriormente expuestas son un repertorio básico de elementos para leer el libro álbum. Pueden servir de carta de navegación o de referente para los educadores al utilizar este artefacto cultural en el aula o para todos aquellos lectores interesados en el tema. Y aunque no se tomen en cuenta todos los puntos al pie de la letra, lo importante es no perder de vista la complejidad y la riqueza de aspectos derivados del juego comunicativo entre el texto y las imágenes. Dejar de lado o menospreciar todas las posibilidades contenidas en los libros álbum es privarnos de disfrutar estas pequeñas "obras de arte" y perder la oportunidad de formar a otro tipo de lectores.

\section{REFERENCIAS}

Andruetto, T. (2012). Benjamino. Ilustrado por Cynthia Orensztajn. Bogotá: Alfaguara.

Browne, E. (1996). La sorpresa de Nandi. Caracas: Ekaré.

Brunhoff, J. (2005). Historia de Babar el elefantito. Bogotá: Alfaguara.

Caldecott, R. (1878, [2007]). The House that Jack Built. London, New York: F. Warne. Recuperado de https://archive.org/ stream/housethatjackbui00cald\#page/n1/mode/2up

Dondis, D. A. (1992) La sintaxis de la imagen. Introducción al alfabeto visual. $10^{a}$ edición. Barcelona: Gustavo Gili.

Eco, U. y Sebeok, T. (1989). El signo de los tres. Dupin, Holmes, Peirce. Barcelona: Lumen.

Falkoner, E. ([1878], 1992). La casa que Jack construyó. Barcelona: Lumen.

Ginzburg, C. (1986). El queso y los gusanos. Barcelona: Muchnik. 
Grimm, J. y Grimm, W. (1984). El pescador y su mujer. Ilustrado por John Howe. Madrid: Anaya.

Hánan, F. (2007). Leer y mirar el libro álbum: ¿un género en construcción? Bogotá: Norma.

Hutchins, P. (2011). El paseo de Rosalía. Sevilla: Kalandraka.

Kandinsky, V. (1975). Punto y línea sobre el plano. Contribución al análisis de los elementos pictóricos. Barcelona: Barral.

Kohan, S. A. (1999). Cómo escribir relatos. Barcelona: Plaza \& Janés.

Leal, P., Martín, I. y Pontes, R. (2005). El cuento. Mérida: Edere.

Lionni, L. (2008). Nadarín. Sevilla: Kalandraka.

Mari, I. (1996). El globito rojo. Barcelona: Lumen.

Müller, J. (2002). El libro en el libro en el libro. Barcelona: Serres.

Nikolajeva, M. y Scott, C. (2006). How Picturebooks Work (Children's Literature and Culture). New York: Routledge.

Oram, H. (1995). En el desván. Ilustraciones de Satoshi Kitamura. México: Fondo de Cultura Económica.

Salisbury, M. y Styles, M. (2012). El arte de ilustrar libros infantiles. Concepto y práctica de la narración visual. Barcelona: Blume.

Santos, M. Á. (1998). Imagen y educación. Buenos Aires: Magisterio del Río de la Plata.

Swan, A. (1995). Bases del diseño gráfico. Barcelona: Gustavo Gili.

Silva-Díaz, M. (2005). Libros que enseñan a leer: álbumes ficcionales y conocimiento literario. (Tesis de doctorado, dirigida por Teresa Colomer) Barcelona: Universidad de Barcelona.

Wiesner, D. (2003). Los tres cerditos. Barcelona: Juventud.

Zaparaín, F. y González, L. D. (2010). Cruce de caminos. Álbumes ilustrados: construcción y lectura. Salamanca: Universidad de Valladolid y Universidad de Castilla-La Mancha.

\section{BIBLIOGRAFÍA COMPLEMENTARIA}

Colomer, T.; Kümmerling-Meibauer B. y Silva-Díaz, M. (Coords.). (2010). Cruce de miradas: nuevas aproximaciones al libro-álbum. Barcelona: Banco del libro-GRETEL.

Colomer, T. y Fittipaldi, M. (Coords.). (2012). La literatura que acoge: inmigración y lectura de álbumes. Barcelona: Banco del libro-GRETEL.

Duran, T. (2009). Álbumes y otras lecturas. Análisis de los libros infantiles. Octaedro: Barcelona.

Laboratorio Internacional Construyendo Lectores. (2006). Compartiendo el libro-álbum. H. Hidalgo (Ed.). Santiago de Chile: Centro Cultural de España. Recuperado de https://docs.google.com/file/d/0B1Q-6klvqTEQN1REODZocTUzWTQ/edit

Silva-Díaz, M. C. (2005). La metaficción como un juego de niños. Una introducción a los álbumes metaficcionales. Caracas: Banco del libro.

Unidad de Currículum y Evaluación; Centro de Recursos para el Aprendizaje-CRA. (2009). Ver para leer. Acercándonos al libro álbum. Santiago de Chile: Ministerio de Educación. Recuperado de http://odas.educarchile.cl/interactivos/ ver para leer.pdf

Varios Autores (1996). El álbum ilustrado (número monográfico). J. Flor Rebanal, J. García Sobrino y D. Gutiérrez del Valle. (Coords.). Peonza: Revista de Literatura Infantil y Juvenil, 39. Recuperado de http://bib.cervantesvirtual.com/ servlet/SirveObras/13505054325249274754491/ima0001.htm

Varios Autores (2005). El libro-álbum. Invención y evolución de un género para niños. Caracas: Banco del libro.

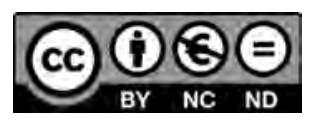

[ 345 ]

enunciación

ISSN 0122-6339・ISSNe 2248-6798・Vol 19, No 2 (julio-diciembre 2014). pp. 333-345 